\title{
Having a Coffee Break: The Impact of Caffeine Consumption on Microglia-Mediated Inflammation in Neurodegenerative Diseases
}

\author{
Maria H. Madeira, ${ }^{1,2}$ Raquel Boia,, ${ }^{1,2}$ António F. Ambrósio, ${ }^{1,2,3}$ and Ana R. Santiago ${ }^{1,2,3}$ \\ ${ }^{1}$ Institute for Biomedical Imaging and Life Sciences (IBILI), Faculty of Medicine, University of Coimbra, 3000-548 Coimbra, Portugal \\ ${ }^{2}$ CNC.IBILI Consortium, University of Coimbra, 3004-504 Coimbra, Portugal \\ ${ }^{3}$ Association for Innovation and Biomedical Research on Light and Image (AIBILI), 3000-548 Coimbra, Portugal \\ Correspondence should be addressed to Ana R. Santiago; asantiago@fmed.uc.pt
}

Received 22 September 2016; Accepted 12 January 2017; Published 31 January 2017

Academic Editor: Luc Vallières

Copyright ( 2017 Maria H. Madeira et al. This is an open access article distributed under the Creative Commons Attribution License, which permits unrestricted use, distribution, and reproduction in any medium, provided the original work is properly cited.

Caffeine is the major component of coffee and the most consumed psychostimulant in the world and at nontoxic doses acts as a nonselective adenosine receptor antagonist. Epidemiological evidence suggests that caffeine consumption reduces the risk of several neurological and neurodegenerative diseases. However, despite the beneficial effects of caffeine consumption in human health and behaviour, the mechanisms by which it impacts the pathophysiology of neurodegenerative diseases still remain to be clarified. A promising hypothesis is that caffeine controls microglia-mediated neuroinflammatory response associated with the majority of neurodegenerative conditions. Accordingly, it has been already described that the modulation of adenosine receptors, namely, the $\mathrm{A}_{2 \mathrm{~A}}$ receptor, affords neuroprotection through the control of microglia reactivity and neuroinflammation. In this review, we will summarize the main effects of caffeine in the modulation of neuroinflammation in neurodegenerative diseases.

\section{Microglial Cells Play Crucial Roles in Neurodegenerative Diseases}

The multitaskers microglial cells are active effectors and regulators of homeostasis in the central nervous system (CNS). Microglial cells constantly survey the surrounding environment, and as primary resident immune cells in the CNS, they respond to the presence of pathogens, stress, or injury [1]. In fact, for decades, it was believed that in homeostatic conditions microglial cells were in a nonreactive resting state, which could be transformed into a reactive state under pathological conditions. Nevertheless, the crucial role of microglial cells in the noninjured CNS has become more evident in recent years, and these cells not only are involved in immune pathological response but are essential during CNS development, participating in crucial processes such as in synaptic pruning $[2,3]$ and synaptic plasticity $[4,5]$. Thus, the so-called resting phenotype should also reflect an active state and should be replaced by surveillance state [6].
Contrasting to the highly ramified organization presented by microglia in the surveillance state, reactive microglial cells are characterized by amoeboid morphology, which favours phagocytosis $[7,8]$. This shift to a more activated phenotype results in increased release of proinflammatory and cytotoxic factors, such as tumour necrosis factor (TNF), interleukin$1 \beta$ (IL-1 $\beta$ ), nitric oxide (NO), and reactive oxygen species (ROS) [9], as well as in increased expression of surface molecules related to the innate immune response, as major histocompatibility complex (MHC) proteins and antigenpresenting receptors [10].

When studying microglial cell reactivity in the context of pathology, one major point is the dichotomy between their contribution to neuroprotection and neurodegeneration. Microglia activation and production of inflammatory mediators are known to be a response to neuronal dysfunction and death to control the damage and to promote recovery (reviewed in [11, 12]). Nevertheless, sustained reactivity of microglial cells has a detrimental role and contributes to 
neurodegeneration, in which neuronal loss is accompanied by increased neuroinflammatory conditions [13-16].

In the two last decades, significant advances have been made in the understanding of the contribution of microglial cells to CNS diseases. The activation of these cells is recognized as a hallmark of a wide variety of neurodegenerative diseases, such as Alzheimer's disease (AD), Parkinson's disease (PD), and multiple sclerosis (MS), and in retinal diseases, such glaucoma, diabetic retinopathy, and age-related macular degeneration (reviewed in $[9,17])$. Hence, suppression of microglial-associated deleterious effects has emerged as a potential therapeutic strategy to prevent neurodegeneration $[18,19]$.

\section{The Modulation of the Adenosinergic System for Therapeutic Intervention in Neurodegenerative Diseases}

Adenosine is a ubiquitously expressed purine nucleoside that acts as a homeostatic factor and a crucial neuromodulator in the CNS. In physiological conditions, the concentration of adenosine in the extracellular fluids is low (30-300 nM), but its levels increase to $10 \mu \mathrm{M}$ or higher during enhanced nerve activity, hypoxia, ischemia, or CNS damage [20]. At high concentrations, adenosine is able to modulate the release of excitotoxic mediators, limit calcium influx, hyperpolarize neurons, and exert modulatory effects on glial cells [21].

Four types of G-coupled receptors coordinate cellular responses to extracellular adenosine: the inhibitory $A_{1}$ and $\mathrm{A}_{3}$ receptors and the facilitatory $\mathrm{A}_{2 \mathrm{~A}}$ and $\mathrm{A}_{2 \mathrm{~B}}$ receptors [22]. These receptors are expressed on astrocytes, microglia, and infiltrating immune cells and regulate the immune response of these cells in the CNS [23-31]. The actions mediated by adenosine in the immune cells may be towards neuronal protection, but adenosine may also promote proinflammatory response, leading to neuronal damage (reviewed [32]).

In the last decades, the neuroprotective properties of adenosine in the CNS have been extensively documented [33-41]. The neuromodulatory effects mediated by adenosine rely on a balanced activation of the inhibitory $A_{1}$ receptor $\left(A_{1} R\right)$ and excitatory $A_{2 A}$ receptor $\left(A_{2 A} R\right)$ [41]. A large body of evidence points to a neuroprotective role of $A_{1} R$ activation, but this receptor is prone to rapid desensitization, limiting the time-lapse of action of possible neuroprotective therapies [41].

Concerning $\mathrm{A}_{2 \mathrm{~A}} \mathrm{R}$, there is an apparent paradox on the role mediated by this receptor in inflammation. In the periphery, activation of $\mathrm{A}_{2 \mathrm{~A}} \mathrm{R}$ signaling suppresses inflammation [42], attenuates pulmonary ischemic injury [43, 44], and improves cardiac dysfunction [45]. In the CNS, $\mathrm{A}_{2 \mathrm{~A}} \mathrm{R}$ controls the release of BDNF from activated microglia [46], and its blockade prevents hippocampal LPS-induced neuroinflammation [47] and prevents IL- $1 \beta$-induced exacerbation of neuronal toxicity [48]. Antagonists $\mathrm{A}_{2 \mathrm{~A}} \mathrm{R}$ prevent retinal microglia reactivity, affording protection to retinal neuronal cells $[26,27]$. Importantly, blockade of $\mathrm{A}_{2 \mathrm{~A}} \mathrm{R}$ has been shown to confer neuroprotection against a broad spectrum of CNS insults $[49,50]$.
While in the periphery, the activation of $\mathrm{A}_{2 \mathrm{~A}} \mathrm{R}$ halts a rapid immune response (acute), in the CNS the activation of $\mathrm{A}_{2 \mathrm{~A}} \mathrm{R}$ aggravates the inflammatory response (chronic conditions) (reviewed in [51]). This dual role of $A_{2 A} R$ might reflect the complexity of actions in distinct cell types present in the CNS, which may lead to distinct effects upon CNS injury $[41,52]$. The mechanisms by which the blockade of $\mathrm{A}_{2 \mathrm{~A}} \mathrm{R}$ is able to impact neuroprotection remains to be clarified, but two leading hypotheses have been explored: the control of glutamate excitotoxicity and the control of microglia-mediated neuroinflammation [40, 41].

The blockade of $\mathrm{A}_{2 \mathrm{~A}} \mathrm{R}$ has emerged as a potential therapeutic strategy, based on its ability to regulate proliferation, chemotaxis, and reactivity of glial cells, affording protection in several brain diseases (reviewed in $[40,50]$ ).

Although less expressed, $\mathrm{A}_{2 \mathrm{~B}} \mathrm{R}$ and $\mathrm{A}_{3} \mathrm{R}$ may also mediate protective effects in the CNS. By acting on $A_{2 B} R$, adenosine has been shown to augment the production of IL-10 by microglial and macrophages cells, while preventing the release of proinflammatory cytokines [53]. The activation of $\mathrm{A}_{3} \mathrm{R}$ has been shown to afford protective effects, namely, after brain ischemia [54] and in retinal neurodegeneration [55].

\section{Caffeine: An Antagonist of Adenosine Receptors with Protective Functions in the CNS}

Caffeine (1,3,7-trimethylxanthine) is the most widely consumed psychostimulant substance in the world, mainly found in dietary sources, such coffee, tea, and energy drinks [56]. Caffeine has been described as a CNS stimulant that promotes wakefulness, enhances mood and cognition, and produces stimulatory effects $[57,58]$. In fact, caffeine exerts beneficial effects on human behaviour, which were not mimicked by the consumption of decaffeinated drinks [59].

Worldwide, it is estimated that caffeine consumption, from all sources, is around 70 to $76 \mathrm{mg} /$ person/day. A single cup of coffee provides a dose of 0.4 to $2.5 \mathrm{mg} / \mathrm{kg}$ of caffeine, leading to a peak serum concentration of 0.25 to $2 \mathrm{mg} / \mathrm{L}$ or approximately 1 to $10 \mu \mathrm{M}$. In humans, $99 \%$ of caffeine is absorbed from the gastrointestinal tract in about $45 \mathrm{~min}$ after ingestion [56]. The first metabolic step, which represents on average $80 \%$ of the total process, is via $\mathrm{N}-3$ demethylation to paraxanthine (1,7-dimethylxanthine) by the cytochrome P450 1A2 enzyme [60] and was recently found to be associated with the variability of caffeine consumption between individuals [61]. Other two important products of caffeine metabolism are theobromine (3,7-dimethylxanthine) and theophylline (1,3-dimethylxanthine), which represent about $16 \%$ of the total metabolites [62]. After long-term consumption of high doses of caffeine, these metabolites can also contribute to its pharmacological actions, since it can result in an accumulation of methylxanthines in the body, due to end-product inhibition of demethylation, and thereby should be also considered when investigating the pharmacological actions of caffeine [63]. 
Most of the studies about the beneficial effects of coffee have been focused largely on caffeine, but coffee contains over 1,000 components that may have neuroprotective effects [64-67]. Interestingly, decaffeinated coffee is protective in Drosophila models of PD [68], suggesting that other coffee constituents may provide neuroprotection. Eicosanoyl-5-hydroxytryptamide, a constituent of coffee, has been demonstrated to ameliorate the phenotype of a PD model associated with decreased protein aggregation and phosphorylation, improved neuronal integrity, and reduced neuroinflammation [69]. Also, chlorogenic acid, trigonelline, and melanoidins are also able to impact gene transcription and regulation of body fat percentage $[70,71]$.

The biochemical mechanisms that underlie the actions of caffeine are dependent on the dose. In the brain, the molecular targets of caffeine at nontoxic doses are the adenosine receptors $A_{1}$ and $A_{2 A}$ [56].

One of the most recognized actions of caffeine is its ability to reduce sleep and sleepiness. Caffeine, acting on $\mathrm{A}_{2 \mathrm{~A}} \mathrm{R}$, promotes wakefulness, as demonstrated by genetic manipulation of the $A_{2 A} R$ in the nucleus accumbens [72].

Ethanol and caffeinated beverages are frequently consumed in combination, a fact that might be due to the popular belief that caffeine can offset the acute intoxicating actions of ethanol. In fact, it has been shown that caffeine is able to attenuate ethanol-induced motor incoordination in rats [73], an effect that was also observed with $A_{1} R$ antagonists, but not with antagonists of $\mathrm{A}_{2 \mathrm{~A}} \mathrm{R}$. Interestingly, caffeine administration also prevents the hypnotic effects induced by ethanol, an effect suggested to be mediated by $\mathrm{A}_{2 \mathrm{~A}} \mathrm{R}$ antagonism, since knockout $(\mathrm{KO})$ mice for this receptor display similar behaviour [74].

Caffeine is also associated with alterations in neurotransmitter release and increase neuronal firing (via $A_{1} R$ ), as well as enhancing dopaminergic transmission (via $\mathrm{A}_{2 \mathrm{~A}} \mathrm{R}$ ), globally affecting neuronal processes associated with mood and cognition (reviewed in [56]). Caffeine has been shown to control synaptic plasticity [75], to revert memory impairments [76, 77], and to prevent mood alteration triggered by chronic stress [78]. Importantly, these effects were also observed in the presence of selective $\mathrm{A}_{2 \mathrm{~A}} \mathrm{R}$ antagonists prompting the critical role of this receptor to the actions of caffeine. Indeed, using $\mathrm{A}_{2 \mathrm{~A}} \mathrm{R}-\mathrm{KO}$ mice, it was recently shown that the neuroprotective effects of caffeine in a $\mathrm{PD}$ model rely on the presence of $\mathrm{A}_{2 \mathrm{~A}} \mathrm{R}$ [79].

Several studies have been demonstrating protective effects of caffeine in patients and animal models of neurodegenerative diseases, mainly by reducing excitotoxicity, apoptosis, and neuroinflammation (reviewed in [80]).

\section{Modulation of Microglia Reactivity and Neuroinflammation with Caffeine}

Since the late 1990s, several studies have shown that caffeine reduces neuroinflammation in models of $\mathrm{AD}$ and $\mathrm{PD}$ (reviewed in [80]). Additionally, epidemiological studies have shown that caffeine might exert neuroprotective effects in humans $[56,81,82]$.
Several studies have also focused their attention on the ability of caffeine to reduce microglia reactivity. In an in vitro system, using the murine BV-2 microglia cell line, it was demonstrated that $2 \mathrm{mM}$ caffeine attenuates the expression of proinflammatory mediators, such as NO and TNF, and their regulatory genes, elicited by lipopolysaccharide (LPS) [83], widely known to induce potent neuroinflammatory responses in the brain [84]. The same study suggests the modulation of extracellular signal-regulated kinase (ERK) signaling cascade and consequent NF- $\kappa \mathrm{B}$ activation as a main pathway for caffeine actions [83], which has been also related to the $\mathrm{A}_{2 \mathrm{~A}} \mathrm{R}$ activation-induced macroglial cell reactivity [85]. In an animal model of inflammation, in which LPS was infused over a period of two or four weeks in the brain, caffeine administration (daily intraperitoneal injection) reduces LPS-induced microglia activation in three regions of the hippocampus, in a dose-dependent manner [86].

Importantly, caffeine alters neuronal functioning in physiological brain conditions, increasing the spontaneous firing (reviewed in [56]). The effects of caffeine in nonneuronal cells in nonpathological conditions have not been extensively studied. It was already described that brain sections of animals administered with caffeine ad libitum in the drinking water have altered microglia density and morphology, as observed by process retraction and enlargement of the cell soma, indicating a more reactive phenotype [87]. The authors suggested that caffeine might prime microglial cells, impacting the transition from the surveillance to the reactive state [88]. Notably, in the retina, caffeine intake does not change microglia reactivity and expression of proinflammatory markers [87].

\section{Beneficial Effects of Caffeine in Alzheimer's Disease: Neuroinflammation and Neuroprotection}

Alzheimer's disease is the most common type of dementia worldwide, clinically characterized by a progressive decline of cognitive functions and memory deficits [89]. The main neuropathological hallmarks of AD are extraneuronal deposition of amyloid-beta $(\mathrm{A} \beta)$ protein in the form of plaques and intraneuronal aggregation of the hyperphosphorylated microtubule-associated protein tau in the form of filaments, mainly in the cortex, hippocampus, and amygdala [90]. Furthermore, a strong neuroinflammatory component has been associated with AD pathology, with increased glial cell reactivity (microgliosis and astrogliosis), activation of both classic and alternate pathways of the complement system, upregulation of inflammatory markers, and increased phagocytic activity [91, 92].

The presence of $\mathrm{A} \beta$ oligomers has been described to lead to microglia-mediated neuroinflammatory response, with alterations in the phagocytic efficiency and sustained overproduction of inflammatory mediators, which may contribute to neurotoxicity and neuronal loss [93]. Indeed, microglia reactivity has been described not only in the brain, but also in the retinas of AD animal models [94] and 
patients [95]. It remains to be elucidated whether microglia activation is a cause or a consequence of $\mathrm{AD}$, but the role of microglia reactivity in the progression of the disease is unquestionable. Hence, interventions targeted to control microglial cell reactivity might delay the progression of $\mathrm{AD}$.

Consumption of caffeine has been associated with reduction in the cognitive decline in healthy subjects (with advanced age) and also AD patients [96-99]. In AD animal models the beneficial effects of caffeine intake include amelioration of cognitive impairments $[100,101]$ and dementia [102].

It has been described that increased caffeine levels in the plasma are associated with reduced inflammatory cytokine levels in the hippocampus [103]. Remarkably, chronic administration of caffeine to a transgenic mouse model of progressive $\mathrm{AD}$-like tau pathology mitigates several proinflammatory and oxidative stress markers in the hippocampus and prevents the development of spatial memory deficits [104].

Disruption of the blood-brain barrier (BBB) is an early pathological event in $\mathrm{AD}[105,106]$ and may potentiate the accumulation of $\mathrm{A} \beta$ in the brain by allowing the transport of $\mathrm{A} \beta$ produced in the periphery [107]. Caffeine administration protects against $\mathrm{AD}$-associated $\mathrm{BBB}$ dysfunction $[106,108]$ and reduces glial cell reactivity at sites of BBB leakage [106]. The effects of caffeine in the control of BBB integrity have been associated with its antagonistic actions on adenosine receptors and consequent inhibition of cyclic adenosine monophosphate (cAMP) activity and control of calcium intracellular stores [108]. Caffeine might control ADassociated increase on inflammatory mediators by reducing glial cell reactivity on the BBB leakage site [106] through a reduction in infiltration of immune cells from the periphery [109].

Moreover, using an animal model showing age-related CNS alterations that includes cognitive impairment, increased neuroinflammatory markers, and neurodegeneration, chronic administration of caffeine improves memory deficits and reduces the expression of ROS and proinflammatory cytokines TNF and IL-1 $\beta$, further conferring antiapoptotic effects [110]. Similarly, the effects of caffeine are mimicked by selective antagonists of $\mathrm{A}_{2 \mathrm{~A}} \mathrm{R}$ [111], suggesting that the actions of caffeine are mediated by the blockade of $\mathrm{A}_{2 \mathrm{~A}} \mathrm{R}$. In accordance, both pharmacological blockade and genetic inactivation of $\mathrm{A}_{2 \mathrm{~A}} \mathrm{R}$ afford neuroprotection against A $\beta$ toxicity [112].

These reports reinforce the crucial importance of $\mathrm{A}_{2 \mathrm{~A}} \mathrm{R}$ in $\mathrm{A} \beta$ toxicity and in the associated microglia reactivity and neuroinflammatory response in the context of $\mathrm{AD}$, demonstrating also prophylactic properties of caffeine and the therapeutic potential of $\mathrm{A}_{2 \mathrm{~A}} \mathrm{R}$ antagonists for the treatment of $\mathrm{AD}[113]$.

\section{Caffeine Modulates Neuroinflammation in Parkinson's Disease: Possible Strategy for Neuroprotection?}

Parkinson's disease (PD) is the second most common progressive neurodegenerative disorder. It is characterized by a progressive loss of dopaminergic neurons of the nigrostriatal pathway with the occurrence of Lewy bodies (abnormal deposits of $\alpha$-synuclein), which clinically translates in muscular rigidity, resting tremor, bradykinesia, and postural instability [114]. The pathogenesis of PD has been also associated with chronic neuroinflammation [115] and oxidative stress [116], both contributing to BBB disruption [116, 117].

The brain is particularly susceptible to oxidative stress due to the high consumption of oxygen [116]. Oxidative stress has been associated with several neurodegenerative diseases, including PD. Indeed, there is evidence from postmortem human samples that oxidative stress might be a primary insult that leads to neuronal damage in PD $[118,119]$. In substantia nigra, microglial cells have been proposed to be the main cells producing oxidative stress products [120], suggesting the involvement of these cells in the pathophysiology of PD. The involvement of neuroinflammation in PD was suggested after observation of increased number of reactive microglial cells and an upregulation of major histocompatibility complex class II (MHC-II) in PD patients [121]. Indeed, reactive microglia and neuroinflammatory response have been strongly associated with dopaminergic cell loss in PD (reviewed in [122-124]). Furthermore, elevated levels of proinflammatory cytokines such as TNF [125], IL-1 $\beta$, and IL6 [126] have been described in the striatum of PD patients. In the 1-methyl-4-phenyl-1,2,3,6-tetrahydropyridine (MPTP) animal model of PD there is evidence demonstrating the neurotoxic contribution of microglia-produced TNF [127], IL-1 $\beta$ [128], IL-6, and NO [129] to the loss of dopaminergic neurons. These proinflammatory cytokines, along with factors released from the dying dopaminergic cells, seem to increase and sustain neuroinflammation, leading to an irreversible loss of dopaminergic neurons (reviewed in [130]). Hence, future therapeutic strategies should consider inhibition of microglia-mediated neuroinflammation, possibly in combination with neurotropic factors, aiming to delay the progression of $\mathrm{PD}$.

Epidemiological studies have been associating the consumption of caffeine with reduced risk of developing PD [131-134]. Using the MPTP mouse model, it was shown that daily intraperitoneal administration of caffeine attenuates microglia reactivity and prevents BBB dysregulation, leading to decreased dopaminergic neuronal loss $[135,136]$. Accordingly, even when introduced in the later phases of the neurodegenerative process, caffeine is also able to attenuate the inflammatory process and microglial cell expression of CD68 (a marker of reactive microglia), which suggests its ability to arrest or delay neuroinflammation and neurodegeneration [135]. Likewise, caffeine, even in low doses, is able to reverse functional motor deficits in PD animal models [137, 138].

Although the mechanisms underlying neuroprotection by caffeine remain a matter of debate, it has been widely suggested that the neuroprotective effects of caffeine involve the antagonism of $\mathrm{A}_{2 \mathrm{~A}} \mathrm{R}[79,139,140]$. Notably, pharmacological blockade of $\mathrm{A}_{2 \mathrm{~A}} \mathrm{R}$ presents similar protective effects to the ones observed with caffeine in several experimental models of PD [35, 140-142]. Indeed, the critical contribution of $\mathrm{A}_{2 \mathrm{~A}} \mathrm{R}$ to caffeine-mediated neuroprotection was recently demonstrated in mice lacking the $\mathrm{A}_{2 \mathrm{~A}} \mathrm{R}$ gene ( $\mathrm{KO}$ mice) and exposed to MPTP. In these animals, caffeine had no effect on 
MPTP toxicity, namely, in striatal neuronal loss and motor activity impairment [79].

The selective $\mathrm{A}_{2 \mathrm{~A}} \mathrm{R}$ antagonists istradefylline (KW 6002) [143] and preladenant (SCH 420814) [144] have been investigated in the past years in clinical trials for PD. The $A_{2 A} R$ antagonists significant ameliorate the motor symptoms, but more studies are required to establish the clinical utility of these drugs $[143,144]$.

Taking into account the contribution of microgliamediated neuroinflammation in the pathophysiology of $\mathrm{PD}$ and the beneficial effects of caffeine and $\mathrm{A}_{2 \mathrm{~A}} \mathrm{R}$ antagonists, one can hypothesize that pharmacologic blockade of $\mathrm{A}_{2 \mathrm{~A}} \mathrm{R}$ might offer potential therapeutic benefit in $\mathrm{PD}$ at the level of motor alterations, neuroinflammatory response, and neuroprotection.

\section{The Effects of Caffeine in Multiple Sclerosis}

Multiple sclerosis (MS) is an autoimmune, inflammatory disease of the CNS and the most common cause of chronic neurologic disability beginning in early to middle adult life [145]. The major pathological hallmarks of MS include dysregulation of $\mathrm{BBB}$, which promotes macrophage and lymphocyte infiltration, and the presence of sclerotic plaques in the CNS [146]. In more advanced stages, the degenerative phase is characterized by demyelination and axonal damage that results in neuronal functional impairment in the brain and in the spinal cord. The demyelination process is associated with inflammation, which can occur through activation of resident astrocytes and microglia and by the inflammatory cytokine products of infiltrating immune cells (lymphocytes or macrophages) [147].

Although the exact role of microglial cells in MS is not completely elucidated, it is recognized that these cells are able to sustain and propagate the inflammatory response during autoimmune inflammation [148]. Reactive microglia, expressing MHC-II, exert functions of antigen-presenting cells during MS, therefore promoting the propagation of the inflammatory process and secretion of cytokine or chemokine [149]. Indeed, the detrimental role of microglia activation in MS models has been demonstrated, with the inhibition of these cells leading to a reduction in the myelin and axonal damage, and also in neurodegeneration $[148,150-$ 152].

Nonetheless, microglial cells not only contribute to the neurodegenerative process, but also play an important role in the promotion of neuroprotection, downregulation of inflammatory process, and stimulation of tissue repair. This complex and dual role might be due to the high heterogeneity of myeloid populations (microglia, monocytes, and infiltrating T-cells), with distinct subtypes and distinct states of microglia reactivity (M1 and M2) associated with different pathologic or protective roles [153-155].

As previously mentioned, several reports have implicated the modulation of adenosine receptors in immune cells to a suppression of the inflammatory response (reviewed by [156]). Indeed, the levels of adenosine are reduced in the plasma of MS patients and the expression of $A_{2 A} R$ and $A_{1} R$ is up- and downregulated, respectively $[157,158]$. Studies in animal models of MS confirmed the decreased expression of $A_{1} R$ in microglial cells and an increase in both pro- and anti-inflammatory mediators $[159,160]$. The administration of caffeine to these animals restores the levels of $A_{1} R$ and attenuates the neuroinflammatory process and demyelination [160]. In accordance with studies in animal models of MS, high consumption of coffee may decrease the risk of developing MS $[65,161]$. The authors suggest the suppression of the neuroinflammatory process and consequent production of proinflammatory cytokines as the mechanism underlying the observed association [65].

Similar to other brain conditions, the levels of $\mathrm{A}_{2 \mathrm{~A}} \mathrm{R}$ have been shown to be upregulated in the brain [162] and in lymphocytes of MS patients [163]. Activation of $A_{2 A} R$ has been associated with a strong anti-inflammatory response by immune cells $[156,164]$. Correspondingly, genetic inactivation of $\mathrm{A}_{2 \mathrm{~A}} \mathrm{R}$ has been reported to enhance the inflammatory cell infiltration and microglial cell activation in cortex, brainstem, and spinal cord in a MS animal model, also increasing demyelination and axonal damage [165]. These results suggest that adenosine acting on $\mathrm{A}_{2 \mathrm{~A}} \mathrm{R}$ triggers neuroprotective effects. Intriguingly, the use of antagonists of $A_{2 A} R$ also affords neuroprotection in a model of MS by reducing lymphocyte infiltration [166]. Indeed, a dual role for $A_{2 A} R$ in autoimmune inflammation has been already described, with activation of $\mathrm{A}_{2 \mathrm{~A}} \mathrm{R}$ leading to prevention of the disease in the early stages, whereas $\mathrm{A}_{2 \mathrm{~A}} \mathrm{R}$ blockade affords protection in later stages by reducing neuroinflammation [167]. These results suggest that $A_{2 A} R$ activity can impact the progression of the disease in multiple cellular and molecular targets, but we must keep in mind the possibility that the genetic deletion and pharmacological inactivation of the receptor produce opposite effects in the pathology. Global genetic deletion of $\mathrm{A}_{2 \mathrm{~A}} \mathrm{R}$ occurs in all cellular elements, whereas the pharmacological blockade is suggested to target preferentially neutrophils and lymphocytes [168], reducing their infiltration and therefore exerting neuroprotective effects, as well as reducing microglia activation $[40,165]$. Therefore, the $\mathrm{A}_{2 \mathrm{~A}} \mathrm{R}$ has been considered a potential target for therapeutic approaches in MS. Still, chronic treatment with caffeine during the degenerative phase of MS animal model provides neuroprotection regardless of the $\mathrm{A}_{2 \mathrm{~A}} \mathrm{R}$ genotype, implying that, in this disease, caffeine acts in a non- $\mathrm{A}_{2 \mathrm{~A}} \mathrm{R}$-dependent manner [169].

\section{Beneficial Properties of Caffeine beyond Brain Neurodegenerative Diseases: A Look into the Retina}

Despite the extensive evidence regarding the effects of caffeine consumption in the brain, very little is known about the effects of caffeine consumption in retinal degeneration [170]. We have shown that caffeine administration reduces retinal neuroinflammation and microglial reactivity in an animal model of retinal degeneration induced by ischemia reperfusion (I-R). Notably, caffeine treatment is also able to prevent retinal neuronal cell apoptosis in these animals [171]. Accordingly, in animals subjected to I-R, pharmacological 


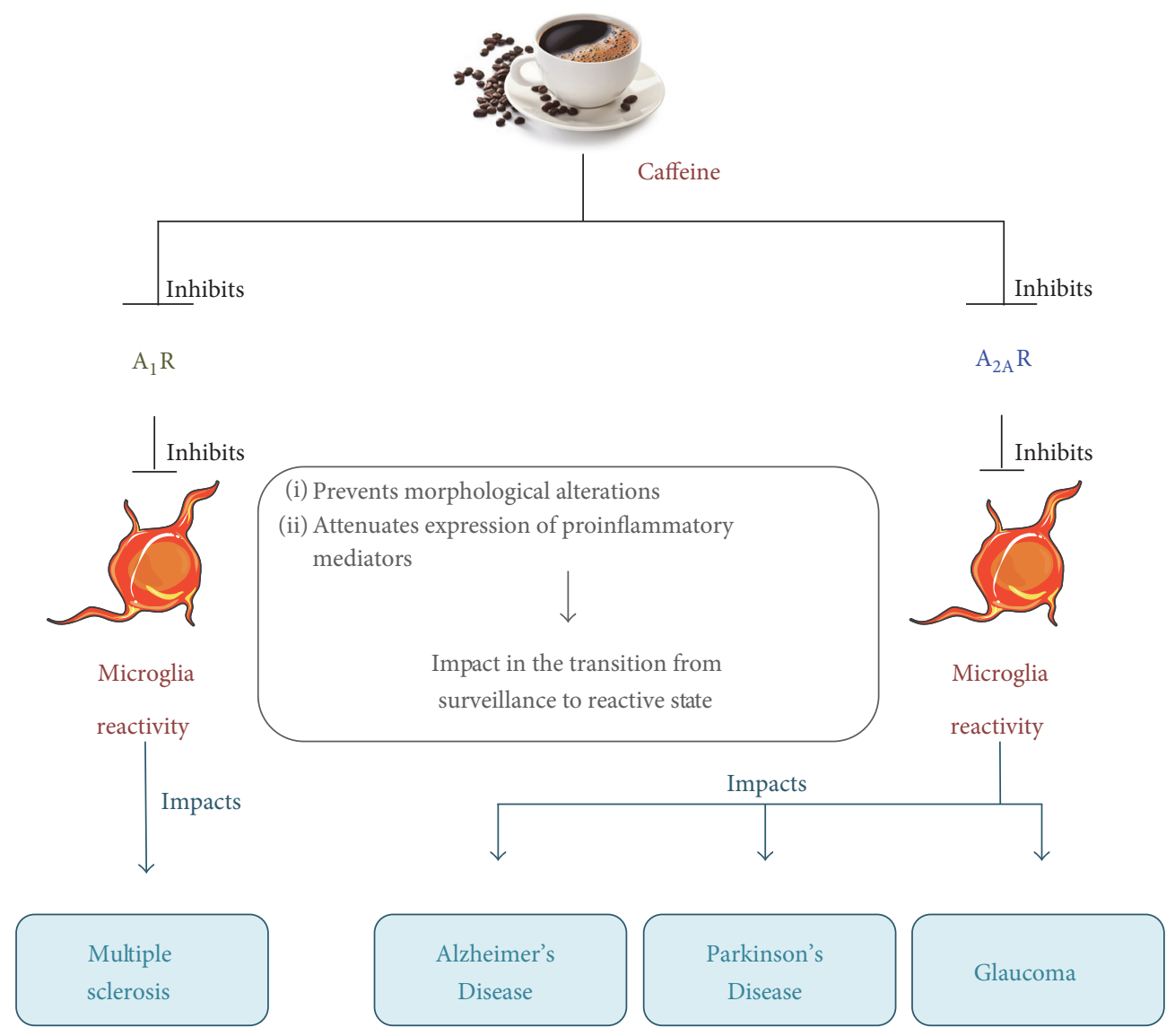

FIGURE 1: Caffeine reduces microglia-mediated inflammatory environment on CNS degenerative diseases. Schematic summary of the effects of caffeine intake on microglia reactivity and the associated CNS degenerative diseases.

blockade of $\mathrm{A}_{2 \mathrm{~A}} \mathrm{R}$ prevents microglia reactivity and neuroinflammatory response [26]. Using retinal organotypic cultures and an I-R animal model we demonstrated that blockade of $\mathrm{A}_{2 \mathrm{~A}} \mathrm{R}$ confers neuroprotection in the retinal through the control of microglia-mediated neuroinflammation [26, 87]. Hence, taking into account the antagonistic effects of caffeine in the $\mathrm{A}_{2 \mathrm{~A}} \mathrm{R}$, one can hypothesize that protection against neuronal apoptosis in the retina afforded by caffeine might also be due to a reduction in microglia reactivity and neuroinflammatory response.

In addition, very recently, we demonstrated that caffeine intake prevents microglia-mediated neuroinflammation and increases the survival of retinal ganglion cells in an animal model of glaucoma [87], suggesting that caffeine may have a prophylactic effect in glaucoma. Still, the understanding of the effects of caffeine and $\mathrm{A}_{2 \mathrm{~A}} \mathrm{R}$ antagonists in retinal neuroinflammation and neurodegeneration is still in a very early stage, but it appears as a promising therapeutic strategy for retinal neurodegenerative diseases [170].

\section{Conclusions}

Coffee is one of the most consumed beverages worldwide and its consumption has been demonstrated to impact human health. Taking in account the beneficial properties of caffeine in neurological and neurodegenerative diseases and the molecular targets of caffeine in the CNS, it is very important to elucidate the effects of caffeine to neuroinflammation.

Antagonists of adenosine receptors, namely, of $\mathrm{A}_{2 \mathrm{~A}} \mathrm{R}$, have been vastly studied in neurodegenerative diseases. One hypothesis that has been gaining attention to explain the protective properties of caffeine and $\mathrm{A}_{2 \mathrm{~A}} \mathrm{R}$ antagonists is the control of microglia-mediated neuroinflammation (Figure 1). Caffeine may block $\mathrm{A}_{2 \mathrm{~A}} \mathrm{R}$ in microglial cells thus controlling exacerbated microglia reactivity and noxious inflammation, providing neuroprotection. Nevertheless, more studies are required to elucidate the cellular and molecular mechanisms of caffeine and its metabolites in the modulation of microgliamediated neuroinflammation in neurodegenerative disorders.

\section{Competing Interests}

The authors declare that they have no competing interests.

\section{Acknowledgments}

Raquel Boia is a recipient of a Ph.D. fellowship from the Foundation for Science and Technology (FCT, Portugal; PD/ 
BD/114115/2015). This work was supported by FCT (PEst-C/ SAU/UI3282/2013 and UID/NEU/04539/2013), Portugal, COMPETE (POCI-01-0145-FEDER-007440), and Manuel Rui Azinhais Nabeiro Lda. Ana Raquel Santiago received a grant from the Global Ophthalmology Awards Program from Bayer HealthCare.

\section{References}

[1] H. Kettenmann, U.-K. Hanisch, M. Noda, and A. Verkhratsky, "Physiology of microglia," Physiological Reviews, vol. 91, no. 2, pp. 461-553, 2011.

[2] D. P. Schafer and B. Stevens, "Phagocytic glial cells: sculpting synaptic circuits in the developing nervous system," Current Opinion in Neurobiology, vol. 23, no. 6, pp. 1034-1040, 2013.

[3] S. Hong, L. Dissing-Olesen, and B. Stevens, "New insights on the role of microglia in synaptic pruning in health and disease," Current Opinion in Neurobiology, vol. 36, pp. 128-134, 2016.

[4] D. P. Schafer, E. K. Lehrman, A. G. Kautzman et al., "Microglia sculpt postnatal neural circuits in an activity and complementdependent manner," Neuron, vol. 74, no. 4, pp. 691-705, 2012.

[5] Y. Wu, L. Dissing-Olesen, B. A. MacVicar, and B. Stevens, "Microglia: dynamic mediators of synapse development and plasticity," Trends in Immunology, vol. 36, no. 10, pp. 605-613, 2015.

[6] U.-K. Hanisch and H. Kettenmann, "Microglia: active sensor and versatile effector cells in the normal and pathologic brain," Nature Neuroscience, vol. 10, no. 11, pp. 1387-1394, 2007.

[7] M. A. Petersen and M. E. Dailey, "Diverse microglial motility behaviors during clearance of dead cells in hippocampal slices," GLIA, vol. 46, no. 2, pp. 195-206, 2004.

[8] N. Stence, M. Waite, and M. E. Dailey, "Dynamics of microglial activation: a confocal time-lapse analysis in hippocampal slices," GLIA, vol. 33, no. 3, pp. 256-266, 2001.

[9] M. E. Lull and M. L. Block, "Microglial activation and chronic neurodegeneration," Neurotherapeutics, vol. 7, no. 4, pp. 354$365,2010$.

[10] F. Aloisi, "Immune function of microglia," GLIA, vol. 36, no. 2, pp. 165-179, 2001.

[11] H. Zhang, F.-W. Wang, L.-L. Yao, and A.-J. Hao, "Microgliafriend or foe," Frontiers in Bioscience-Scholar, vol. 3, no. 3, pp. 869-883, 2011.

[12] Z. Chen and B. D. Trapp, "Microglia and neuroprotection," Journal of Neurochemistry, vol. 136, supplement 1, pp. 10-17, 2016.

[13] R. E. Mrak and W. S. T. Griffin, "Glia and their cytokines in progression of neurodegeneration," Neurobiology of Aging, vol. 26, no. 3, pp. 349-354, 2005.

[14] S. A. Sargsyan, P. N. Monk, and P. J. Shaw, "Microglia as potential contributors to motor neuron injury in amyotrophic lateral sclerosis," GLIA, vol. 51, no. 4, pp. 241-253, 2005.

[15] K. Biber, T. Owens, and E. Boddeke, "What is microglia neurotoxicity (Not)?” GLIA, vol. 62, no. 6, pp. 841-854, 2014.

[16] M. L. Block, L. Zecca, and J.-S. Hong, "Microglia-mediated neurotoxicity: uncovering the molecular mechanisms," Nature Reviews Neuroscience, vol. 8, no. 1, pp. 57-69, 2007.

[17] M. H. Madeira, R. Boia, P. F. Santos, A. F. Ambrósio, and A. R. Santiago, "Contribution of microglia-mediated neuroinflammation to retinal degenerative diseases," Mediators of Inflammation, vol. 2015, Article ID 673090, 15 pages, 2015.

[18] T. Möller and H. W. G. M. Boddeke, "Glial cells as drug targets: what does it take?” GLIA, vol. 64, no. 10, pp. 1742-1754, 2016.
[19] E. E. Spangenberg and K. N. Green, "Inflammation in Alzheimer's disease: lessons learned from microglia-depletion models," Brain, Behavior, and Immunity, 2016.

[20] R. A. Cunha, "Adenosine as a neuromodulator and as a homeostatic regulator in the nervous system: different roles, different sources and different receptors," Neurochemistry International, vol. 38, no. 2, pp. 107-125, 2001.

[21] N. Rebola, R. J. Rodrigues, C. R. Oliveira, and R. A. Cunha, "Different roles of adenosine A1, A2A and A 3 receptors in controlling kainate-induced toxicity in cortical cultured neurons," Neurochemistry International, vol. 47, no. 5, pp. 317-325, 2005.

[22] J.-F. Chen, C.-F. Lee, and Y. Chern, "Adenosine receptor neurobiology: overview," International Review of Neurobiology, vol. 119, pp. 1-49, 2014.

[23] L. Antonioli, C. Blandizzi, P. Pacher, and G. Haskó, "Immunity, inflammation and cancer: a leading role for adenosine," Nature Reviews Cancer, vol. 13, no. 12, pp. 842-857, 2013.

[24] D. Boison, J.-F. Chen, and B. B. Fredholm, "Adenosine signaling and function in glial cells," Cell Death and Differentiation, vol. 17, no. 7, pp. 1071-1082, 2010.

[25] O. Björklund, M. Shang, I. Tonazzini, E. Daré, and B. B. Fredholm, "Adenosine A1 and A3 receptors protect astrocytes from hypoxic damage," European Journal of Pharmacology, vol. 596, no. 1-3, pp. 6-13, 2008.

[26] M. H. Madeira, R. Boia, F. Elvas et al., "Selective A2A receptor antagonist prevents microglia-mediated neuroinflammation and protects retinal ganglion cells from high intraocular pressure-induced transient ischemic injury," Translational Research, vol. 169, pp. 112-128, 2016.

[27] M. H. Madeira, F. Elvas, R. Boia et al., "Adenosine $A_{2 A} R$ blockade prevents neuroinflammation-induced death of retinal ganglion cells caused by elevated pressure," Journal of Neuroinflammation, vol. 12, no. 1, article 115, 2015.

[28] C. Hammarberg, G. Schulte, and B. B. Fredholm, "Evidence for functional adenosine $\mathrm{A}_{3}$ receptors in microglia cells," Journal of Neurochemistry, vol. 86, no. 4, pp. 1051-1054, 2003.

[29] E. Daré, G. Schulte, O. Karovic, C. Hammarberg, and B. B. Fredholm, "Modulation of glial cell functions by adenosine receptors," Physiology and Behavior, vol. 92, no. 1-2, pp. 15-20, 2007.

[30] L. Luongo, F. Guida, R. Imperatore et al., "The A1 adenosine receptor as a new player in microglia physiology," GLIA, vol. 62, no. 1, pp. 122-132, 2014.

[31] M.-C. Peakman and S. J. Hill, "Adenosine $A_{2 B}$-receptormediated cyclic AMP accumulation in primary rat astrocytes," British Journal of Pharmacology, vol. 111, no. 1, pp. 191-198, 1994.

[32] M. R. Blackburn, C. O. Vance, E. Morschl, and C. N. Wilson, "Adenosine receptors and inflammation," Handbook of Experimental Pharmacology, vol. 193, pp. 215-269, 2009.

[33] M. P. Abbracchio and F. Cattabeni, "Brain adenosine receptors as targets for therapeutic intervention in neurodegenerative diseases," Annals of the New York Academy of Sciences, vol. 890, pp. 79-92, 1999.

[34] J. Wardas, "Neuroprotective role of adenosine in the CNS," Polish Journal of Pharmacology, vol. 54, no. 4, pp. 313-326, 2002.

[35] K. Ikeda, M. Kurokawa, S. Aoyama, and Y. Kuwana, "Neuroprotection by adenosine $\mathrm{A} 2 \mathrm{~A}$ receptor blockade in experimental models of Parkinson's disease," Journal of Neurochemistry, vol. 80, no. 2, pp. 262-270, 2002. 
[36] T. W. Stone, S. Ceruti, and M. P. Abbracchio, "Adenosine receptors and neurological disease: neuroprotection and neurodegeneration," Handbook of Experimental Pharmacology, vol. 193, pp. 535-587, 2009.

[37] E. Ongini, M. Adami, C. Ferri, and R. Bertorelli, "Adenosine $\mathrm{A}_{2 A}$ receptors and neuroprotection," Annals of the New York Academy of Sciences, vol. 825, pp. 30-48, 1997.

[38] J.-F. Chen, P. K. Sonsalla, F. Pedata et al., "Adenosine $A_{2 A}$ receptors and brain injury: broad spectrum of neuroprotection, multifaceted actions and 'fine tuning' modulation," Progress in Neurobiology, vol. 83, no. 5, pp. 310-331, 2007.

[39] R. A. Cunha, "How does adenosine control neuronal dysfunction and neurodegeneration?" Journal of Neurochemistry, 2016.

[40] A. R. Santiago, F. I. Baptista, P. F. Santos et al., "Role of microglia adenosine $\mathrm{A}_{2 A}$ receptors in retinal and brain neurodegenerative diseases," Mediators of Inflammation, vol. 2014, Article ID 465694, 13 pages, 2014.

[41] R. A. Cunha, "Neuroprotection by adenosine in the brain: from $A_{1}$ receptor activation to $A_{2 A}$ receptor blockade," Purinergic Signalling, vol. 1, no. 2, pp. 111-134, 2005.

[42] M. V. Sitkovsky, "Use of the $\mathrm{A}_{2 \mathrm{~A}}$ adenosine receptor as a physiological immunosuppressor and to engineer inflammation in vivo," Biochemical Pharmacology, vol. 65, no. 4, pp. 493-501, 2003.

[43] D. J. Lapar, V. E. Laubach, A. Emaminia et al., "Pretreatment strategy with adenosine A2A receptor agonist attenuates reperfusion injury in a preclinical porcine lung transplantation model," Journal of Thoracic and Cardiovascular Surgery, vol. 142, no. 4, pp. 887-894, 2011.

[44] T. B. Reece, P. I. Ellman, T. S. Maxey et al., "Adenosine $\mathrm{A}_{2 A}$ receptor activation reduces inflammation and preserves pulmonary function in an in vivo model of lung transplantation," Journal of Thoracic and Cardiovascular Surgery, vol. 129, no. 5, pp. 11371143, 2005.

[45] T. B. Reece, V. E. Laubach, C. G. Tribble et al., "Adenosine $A_{2 A}$ receptor agonist improves cardiac dysfunction from pulmonary ischemia-reperfusion injury," Annals of Thoracic Surgery, vol. 79, no. 4, pp. 1189-1195, 2005.

[46] C. Gomes, R. Ferreira, J. George et al., "Activation of microglial cells triggers a release of brain-derived neurotrophic factor (BDNF) inducing their proliferation in an adenosine $A_{2 A}$ receptor-dependent manner: $A_{2 A}$ receptor blockade prevents BDNF release and proliferation of microglia," Journal of Neuroinflammation, vol. 10, article 16, 2013.

[47] N. Rebola, A. P. Simões, P. M. Canas et al., "Adenosine $\mathrm{A}_{2 \mathrm{~A}}$ receptors control neuroinflammation and consequent hippocampal neuronal dysfunction," Journal of Neurochemistry, vol. 117, no. 1, pp. 100-111, 2011.

[48] A. P. Simões, J. A. Duarte, F. Agasse et al., "Blockade of adenosine $A_{2 A}$ receptors prevents interleukin- $1 \beta$-induced exacerbation of neuronal toxicity through a p38 mitogen-activated protein kinase pathway," Journal of Neuroinflammation, vol. 9, article 204, 2012.

[49] S.-S. Dai and Y.-G. Zhou, "Adenosine 2A receptor: a crucial neuromodulator with bidirectional effect in neuroinflammation and brain injury," Reviews in the Neurosciences, vol. 22, no. 2, pp. 231-239, 2011.

[50] C. V. Gomes, M. P. Kaster, A. R. Tomé, P. M. Agostinho, and R. A. Cunha, "Adenosine receptors and brain diseases: neuroprotection and neurodegeneration," Biochimica et Biophysica Acta-Biomembranes, vol. 1808, no. 5, pp. 1380-1399, 2011.
[51] R. A. Cunha, J. F. Chen, and M. V. Sitkovsky, "Opposite modulation of peripheral inflammation and neuroinflammation by adenosine A2A receptors," in Interaction between Neurons and Glia in Aging and Disease, pp. 53-79, Springer, New York, NY, USA, 2007.

[52] J.-F. Chen, H. K. Eltzschig, and B. B. Fredholm, "Adenosine receptors as drug targets-what are the challenges?" Nature Reviews Drug Discovery, vol. 12, no. 4, pp. 265-286, 2013.

[53] W. Wei, C. Du, J. Lv et al., "Blocking $\mathrm{A}_{2 B}$ adenosine receptor alleviates pathogenesis of experimental autoimmune encephalomyelitis via inhibition of IL-6 production and Th17 differentiation," Journal of Immunology, vol. 190, no. 1, pp. 138146, 2013.

[54] G.-J. Chen, B. K. Harvey, H. Shen, J. Chou, A. Victor, and Y. Wang, "Activation of adenosine A3 receptors reduces ischemic brain injury in rodents," Journal of Neuroscience Research, vol. 84, no. 8, pp. 1848-1855, 2006.

[55] J. Galvao, F. Elvas, T. Martins, M. F. Cordeiro, A. F. Ambrósio, and A. R. Santiago, "Adenosine A3 receptor activation is neuroprotective against retinal neurodegeneration," Experimental Eye Research, vol. 140, pp. 65-74, 2015.

[56] B. B. Fredholm, K. Bättig, J. Holmén, A. Nehlig, and E. E. Zvartau, "Actions of caffeine in the brain with special reference to factors that contribute to its widespread use," Pharmacological Reviews, vol. 51, no. 1, pp. 83-133, 1999.

[57] A. Nehlig, J.-L. Daval, and G. Debry, "Caffeine and the central nervous system: mechanisms of action, biochemical, metabolic and psychostimulant effects," Brain Research Reviews, vol. 17, no. 2, pp. 139-170, 1992.

[58] C. F. Haskell, D. O. Kennedy, K. A. Wesnes, and A. B. Scholey, "Cognitive and mood improvements of caffeine in habitual consumers and habitual non-consumers of caffeine," Psychopharmacology, vol. 179, no. 4, pp. 813-825, 2005.

[59] A. Smith, "Effects of caffeine on human behavior," Food and Chemical Toxicology, vol. 40, no. 9, pp. 1243-1255, 2002.

[60] L. Gu, F. J. Gonzalez, W. Kalow, and B. K. Tang, "Biotransformation of caffeine, paraxanthine, theobromine and theophylline by cDNA-expressed human CYP1A2 and CYP2E1," Pharmacogenetics, vol. 2, no. 2, pp. 73-77, 1992.

[61] S. Denden, B. Bouden, A. Haj Khelil, J. Ben Chibani, and M. H. Hamdaoui, "Gender and ethnicity modify the association between the CYP1A2 rs762551 polymorphism and habitual coffee intake: evidence from a meta-analysis," Genetics and Molecular Research, vol. 15, no. 2, 2016.

[62] N. L. Benowitz, P. Jacob III, H. Mayan, and C. Denaro, "Sympathomimetic effects of paraxanthine and caffeine in humans," Clinical Pharmacology and Therapeutics, vol. 58, no. 6, pp. 684691, 1995.

[63] C. P. Denaro, C. R. Brown, M. Wilson, P. Jacob III, and N. L. Benowitz, "Dose-dependency of caffeine metabolism with repeated dosing," Clinical Pharmacology and Therapeutics, vol. 48, no. 3, pp. 277-285, 1990.

[64] M. Lee, E. G. McGeer, and P. L. McGeer, "Quercetin, not caffeine, is a major neuroprotective component in coffee," Neurobiology of Aging, vol. 46, pp. 113-123, 2016.

[65] A. K. Hedström, E. M. Mowry, M. A. Gianfrancesco et al., "High consumption of coffee is associated with decreased multiple sclerosis risk; results from two independent studies," Journal of Neurology, Neurosurgery and Psychiatry, vol. 87, no. 5, pp. 454460, 2016. 
[66] Y. Mikami and T. Yamazawa, "Chlorogenic acid, a polyphenol in coffee, protects neurons against glutamate neurotoxicity," Life Sciences, vol. 139, Article ID 14470, pp. 69-74, 2015.

[67] G. Basurto-Islas, J. Blanchard, Y. C. Tung et al., "Therapeutic benefits of a component of coffee in a rat model of Alzheimer's disease," Neurobiology of Aging, vol. 35, no. 12, pp. 2701-2712, 2014.

[68] K. Trinh, L. Andrews, J. Krause et al., "Decaffeinated coffee and nicotine-free tobacco provide neuroprotection in Drosophila models of Parkinson's disease through an NRF2-dependent mechanism," Journal of Neuroscience, vol. 30, no. 16, pp. 55255532, 2010.

[69] K.-W. Lee, J.-Y. Im, J.-M. Woo et al., "Neuroprotective and antiinflammatory properties of a coffee component in the MPTP model of Parkinson's disease," Neurotherapeutics, vol. 10, no. 1, pp. 143-153, 2013.

[70] I. A. Ludwig, M. N. Clifford, M. E. J. Lean, H. Ashihara, and A. Crozier, "Coffee: biochemistry and potential impact on health," Food and Function, vol. 5, no. 8, pp. 1695-1717, 2014.

[71] B. Muqaku, A. Tahir, P. Klepeisz et al., "Coffee consumption modulates inflammatory processes in an individual fashion," Molecular Nutrition and Food Research, vol. 60, no. 12, pp. 25292541, 2016.

[72] M. Lazarus, H.-Y. Shen, Y. Cherasse et al., "Arousal effect of caffeine depends on adenosine $\mathrm{A}_{2 A}$ receptors in the shell of the nucleus accumbens," Journal of Neuroscience, vol. 31, no. 27, pp. 10067-10075, 2011.

[73] L. Connole, A. Harkin, and M. Maginn, "Adenosine A1 receptor blockade mimics caffeine's attenuation of ethanol-induced motor incoordination," Basic \& Clinical Pharmacology \& Toxicology, vol. 95, no. 6, pp. 299-304, 2004.

[74] M. El Yacoubi, C. Ledent, M. Parmentier, J. Costentin, and J.-M. Vaugeois, "Caffeine reduces hypnotic effects of alcohol through adenosine A 2A receptor blockade," Neuropharmacology, vol. 45, no. 7, pp. 977-985, 2003.

[75] A. P. Simões, N. J. Machado, N. Gonçalves et al., "Adenosine A2A receptors in the amygdala control synaptic plasticity and contextual fear memory," Neuropsychopharmacology, vol. 41, no. 12, pp. 2862-2871, 2016.

[76] N. J. Machado, A. P. Simões, H. B. Silva et al., "Caffeine reverts memory but not mood impairment in a depressionprone mouse strain with up-regulated adenosine a2a receptor in hippocampal glutamate synapses," Molecular Neurobiology, pp. 1-12, 2016.

[77] R. A. Cunha and P. M. Agostinho, "Chronic caffeine consumption prevents memory disturbance in different animal models of memory decline," Journal of Alzheimer's Disease, vol. 20, no. 1, pp. S95-S116, 2010.

[78] M. P. Kaster, N. J. Machado, H. B. Silva et al., "Caffeine acts through neuronal adenosine $\mathrm{A}_{2 A}$ receptors to prevent mood and memory dysfunction triggered by chronic stress," Proceedings of the National Academy of Sciences of the United States of America, vol. 112, no. 25, pp. 7833-7838, 2015.

[79] K. Xu, D. G. Di Luca, M. Orrú, Y. Xu, J.-F. Chen, and M. A. Schwarzschild, "Neuroprotection by caffeine in the MPTP model of parkinson's disease and its dependence on adenosine A2A receptors," Neuroscience, vol. 322, pp. 129-137, 2016.

[80] M. Rivera-Oliver and M. Díaz-Ríos, "Using caffeine and other adenosine receptor antagonists and agonists as therapeutic tools against neurodegenerative diseases: a review," Life Sciences, vol. 101, no. 1-2, pp. 1-9, 2014.
[81] M. Morelli, A. R. Carta, A. Kachroo, and M. A. Schwarzschild, "Pathophysiological roles for purines. Adenosine, caffeine and urate," Progress in Brain Research, vol. 183, no. C, pp. 183-208, 2010.

[82] J.-F. Chen and Y. Chern, "Impacts of methylxanthines and adenosine receptors on neurodegeneration: human and experimental studies," Handbook of Experimental Pharmacology, vol. 200, pp. 267-310, 2011.

[83] C.-H. Kang, R. G. P. T. Jayasooriya, M. G. Dilshara et al., "Caffeine suppresses lipopolysaccharide-stimulated BV2 microglial cells by suppressing Akt-mediated NF- $\kappa \mathrm{B}$ activation and ERK phosphorylation," Food and Chemical Toxicology, vol. 50, no. 12, pp. 4270-4276, 2012.

[84] P.-B. Andersson, V. H. Perry, and S. Gordon, "The acute inflammatory response to lipopolysaccharide in cns parenchyma differs from that in other body tissues," Neuroscience, vol. 48, no. 1, pp. 169-186, 1992.

[85] R.-H. Ke, J. Xiong, Y. Liu, and Z.-R. Ye, "Adenosine $A_{2 A}$ receptor induced gliosis via Akt/NF- $\kappa \mathrm{B}$ pathway in vitro," Neuroscience Research, vol. 65, no. 3, pp. 280-285, 2009.

[86] H. M. Brothers, Y. Marchalant, and G. L. Wenk, "Caffeine attenuates lipopolysaccharide-induced neuroinflammation," Neuroscience Letters, vol. 480, no. 2, pp. 97-100, 2010.

[87] M. H. Madeira, A. Ortin-Martinez, F. Nadal-Nícolas et al., "Caffeine administration prevents retinal neuroinflammation and loss of retinal ganglion cells in an animal model of glaucoma," Scientific Reports, vol. 6, Article ID 27532, 2016.

[88] R. Steger, A. Kamal, S. Lutchman, L. Intrabartolo, R. Sohail, and J. C. Brumberg, "Chronic caffeine ingestion causes microglia activation, but not proliferation in the healthy brain," Brain Research Bulletin, vol. 106, pp. 39-46, 2014.

[89] C. Reitz and R. Mayeux, "Alzheimer disease: epidemiology, diagnostic criteria, risk factors and biomarkers," Biochemical Pharmacology, vol. 88, no. 4, pp. 640-651, 2014.

[90] A. Lloret, T. Fuchsberger, E. Giraldo, and J. Viña, "Molecular mechanisms linking amyloid $\beta$ toxicity and Tau hyperphosphorylation in Alzheimers disease," Free Radical Biology and Medicine, vol. 83, pp. 186-191, 2015.

[91] M. D. Ikonomovic, W. E. Klunk, E. E. Abrahamson et al., "Postmortem correlates of in vivo PiB-PET amyloid imaging in a typical case of Alzheimer's disease," Brain, vol. 131, no. 6, pp. 1630-1645, 2008.

[92] M. Bobinski, M. J. De Leon, J. Wegiel et al., "The histological validation of post mortem magnetic resonance imagingdetermined hippocampal volume in Alzheimer's disease," Neuroscience, vol. 95, no. 3, pp. 721-725, 1999.

[93] X.-D. Pan, Y.-G. Zhu, N. Lin et al., "Microglial phagocytosis induced by fibrillar $\beta$-amyloid is attenuated by oligomeric $\beta$ amyloid: implications for Alzheimer's disease," Molecular Neurodegeneration, vol. 6, no. 1, article 45, 2011.

[94] A. Ning, J. Cui, E. To, K. H. Ashe, and J. Matsubara, "Amyloid$\beta$ deposits lead to retinal degeneration in a mouse model of Alzheimer disease," Investigative Ophthalmology and Visual Science, vol. 49, no. 11, pp. 5136-5143, 2008.

[95] S. C. K. Liew, P. L. Penfold, J. M. Provis, M. C. Madigan, and F. A. Blllson, "Modulation of MHC class II expression in the absence of lymphocytic infiltrates in alzheimer's retinae," Journal of Neuropathology and Experimental Neurology, vol. 53, no. 2, pp. 150-157, 1994.

[96] M. Johnson-Kozlow, D. Kritz-Silverstein, E. Barrett-Connor, and D. Morton, "Coffee consumption and cognitive function 
among older adults," American Journal of Epidemiology, vol. 156, no. 9, pp. 842-850, 2002.

[97] K. Ritchie, I. Carrière, A. De Mendonça et al., "The neuroprotective effects of caffeine: a prospective population study (the Three City Study)," Neurology, vol. 69, no. 6, pp. 536-545, 2007.

[98] B. M. van Gelder, B. Buijsse, M. Tijhuis et al., "Coffee consumption is inversely associated with cognitive decline in elderly European men: The FINE Study," European Journal of Clinical Nutrition, vol. 61, no. 2, pp. 226-232, 2007.

[99] L. Arab, F. Khan, and H. Lam, "Epidemiologic evidence of a relationship between tea, coffee, or caffeine consumption and cognitive decline," Advances in Nutrition, vol. 4, no. 1, pp. 115122, 2013.

[100] G. W. Arendash, T. Mori, C. Cao et al., "Caffeine reverses cognitive impairment and decreases brain amyloid- $\beta$ levels in aged alzheimer's disease mice," Journal of Alzheimer's Disease, vol. 17, no. 3, pp. 661-680, 2009.

[101] G. W. Arendash, W. Schleif, K. Rezai-Zadeh et al., "Caffeine protects Alzheimer's mice against cognitive impairment and reduces brain $\beta$-amyloid production," Neuroscience, vol. 142, no. 4, pp. 941-952, 2006.

[102] M. H. Eskelinen and M. Kivipelto, "Caffeine as a protective factor in dementia and Alzheimer's disease," Journal of Alzheimer's Disease, vol. 20, no. 1, pp. S167-S174, 2010.

[103] C. Cao, X. Cirrito Lin Jr., L. Wang et al., "Caffeine suppresses amyloid-beta levels in plasma and brain of Alzheimer's disease transgenic mice," Journal of Alzheimer's Disease, vol. 17, no. 3, pp. 681-697, 2009.

[104] C. Laurent, S. Eddarkaoui, M. Derisbourg et al., "Beneficial effects of caffeine in a transgenic model of Alzheimer's diseaselike tau pathology," Neurobiology of Aging, vol. 35, no. 9, pp. 2079-2090, 2014.

[105] M. Ujiie, D. L. Dickstein, D. A. Carlow, and W. A. Jefferies, "Blood-brain barrier permeability precedes senile plaque formation in an Alzheimer disease model," Microcirculation, vol. 10, no. 6, pp. 463-470, 2003.

[106] X. Chen, J. W. Gawryluk, J. F. Wagener, O. Ghribi, and J. D. Geiger, "Caffeine blocks disruption of blood brain barrier in a rabbit model of Alzheimer's disease," Journal of Neuroinflammation, vol. 5, article no. 12, 2008.

[107] Y.-M. Kuo, T. A. Kokjohn, M. D. Watson et al., "Elevated A $\beta 42$ in skeletal muscle of Alzheimer disease patients suggests peripheral alterations of A $\beta$ PP metabolism," American Journal of Pathology, vol. 156, no. 3, pp. 797-805, 2000.

[108] X. Chen, O. Ghribi, and J. D. Geiger, "Caffeine protects against disruptions of the blood-brain barrier in animal models of Alzheimer's and Parkinson's diseases," Journal of Alzheimer's Disease, vol. 20, no. 1, pp. S127-S141, 2010.

[109] I. G. Farkas, A. Czigner, E. Farkas et al., "Beta-amyloid peptideinduced blood-brain barrier disruption facilitates T-cell entry into the rat brain," Acta Histochemica, vol. 105, no. 2, pp. 115$125,2003$.

[110] F. Ullah, T. Ali, N. Ullah, and M. O. Kim, "Caffeine prevents dgalactose-induced cognitive deficits, oxidative stress, neuroinflammation and neurodegeneration in the adult rat brain," Neurochemistry International, vol. 90, pp. 114-124, 2015.

[111] O. P. Dall'Igna, P. Fett, M. W. Gomes, D. O. Souza, R. A. Cunha, and D. R. Lara, "Caffeine and adenosine A2a receptor antagonists prevent $\beta$-amyloid (25-35)-induced cognitive deficits in mice," Experimental Neurology, vol. 203, no. 1, pp. 241-245, 2007.
[112] P. M. Canas, L. O. Porciúncula, G. M. A. Cunha et al., "Adenosine $\mathrm{A}_{2 \mathrm{~A}}$ receptor blockade prevents synaptotoxicity and memory dysfunction caused by $\beta$-amyloid peptides via $\mathrm{p} 38$ mitogen-activated protein kinase pathway," Journal of Neuroscience, vol. 29, no. 47, pp. 14741-14751, 2009.

[113] G. W. Arendash and C. Cao, "Caffeine and coffee as therapeutics against Alzheimer's disease," Journal of Alzheimer's Disease, vol. 20, supplement 1, pp. S117-S126, 2010.

[114] T. Klockgether, "Parkinson's disease: clinical aspects," Cell and Tissue Research, vol. 318, no. 1, pp. 115-120, 2004.

[115] E. C. Hirsch, S. Hunot, and A. Hartmann, "Neuroinflammatory processes in Parkinson's disease," Parkinsonism and Related Disorders, vol. 11, supplement 1, pp. S9-S15, 2005.

[116] A. Hald and J. Lotharius, "Oxidative stress and inflammation in Parkinson's disease: is there a causal link?" Experimental Neurology, vol. 193, no. 2, pp. 279-290, 2005.

[117] R. Kortekaas, K. L. Leenders, J. C. H. Van Oostrom et al., "Blood-brain barrier dysfunction in Parkinsonian midbrain in vivo," Annals of Neurology, vol. 57, no. 2, pp. 176-179, 2005.

[118] P. Jenner, "Oxidative mechanisms in nigral cell death in Parkinson's disease," Movement Disorders, vol. 13, no. 1, pp. 24-34, 1998.

[119] P. Jenner and C. W. Olanow, "The pathogenesis of cell death in Parkinson's disease," Neurology, vol. 66, no. 10, supplement 4, pp. S24-S30, 2006.

[120] H. Miwa, T. Kubo, S. Morita, I. Nakanishi, and T. Kondo, "Oxidative stress and microglial activation in substantia nigra following striatal MPP+," NeuroReport, vol. 15, no. 6, pp. 10391044, 2004.

[121] P. L. McGeer, S. Itagaki, B. E. Boyes, and E. G. McGeer, "Reactive microglia are positive for HLA-DR in the substantia nigra of Parkinson's and Alzheimer's disease brains," Neurology, vol. 38, no. 8, pp. 1285-1291, 1988.

[122] P. S. Whitton, "Inflammation as a causative factor in the aetiology of Parkinson's disease," British Journal of Pharmacology, vol. 150, no. 8, pp. 963-976, 2007.

[123] E. C. Hirsch, T. Breidert, E. Rousselet, S. Hunot, A. Hartmann, and P. P. Michel, "The role of glial reaction and inflammation in Parkinson's disease," Annals of the New York Academy of Sciences, vol. 991, pp. 214-228, 2003.

[124] A. Hartmann, S. Hunot, and E. C. Hirsch, "Inflammation and dopaminergic neuronal loss in Parkinson's disease: a complex matter," Experimental Neurology, vol. 184, no. 2, pp. 561-564, 2003.

[125] M. Mogi, A. Togari, K.-I. Tanaka, N. Ogawa, H. Ichinose, and T. Nagatsu, "Increase in level of tumor necrosis factor (TNF)$\alpha$ in 6- hydroxydopamine-lesioned striatum in rats without influence of systemic L- DOPA on the TNF- $\alpha$ induction," Neuroscience Letters, vol. 268, no. 2, pp. 101-104, 1999.

[126] D. Blum-Degena, T. Müller, W. Kuhn, M. Gerlach, H. Przuntek, and P. Riederer, "Interleukin- $1 \beta$ and interleukin- 6 are elevated in the cerebrospinal fluid of Alzheimer's and de novo Parkinson's disease patients," Neuroscience Letters, vol. 202, no. 1-2, pp. 17-20, 1995.

[127] K. Sriram, J. M. Matheson, S. A. Benkovic, D. B. Miller, M. I. Luster, and J. P. O'Callaghan, "Mice deficient in TNF receptors are protected against dopaminergic neurotoxicity: implications for Parkinson's disease," The FASEB journal, vol. 16, no. 11, pp. 1474-1476, 2002. 
[128] M.-J. Bian, L.-M. Li, M. Yu, J. Fei, and F. Huang, "Elevated interleukin-1 $\beta$ induced by 1-methyl-4-phenyl-1,2,3,6tetrahydropyridine aggravating dopaminergic neurodegeneration in old male mice," Brain Research, vol. 1302, pp. 256-264, 2009.

[129] D. D. Lofrumento, C. Saponaro, A. Cianciulli et al., "MPTPinduced neuroinflammation increases the expression of proinflammatory cytokines and their receptors in mouse brain," NeuroImmunoModulation, vol. 18, no. 2, pp. 79-88, 2010.

[130] C. F. Orr, D. B. Rowe, and G. M. Halliday, "An inflammatory review of Parkinson's disease," Progress in Neurobiology, vol. 68, no. 5, pp. 325-340, 2002.

[131] M. A. Hernán, B. Takkouche, F. Caamaño-Isorna, and J. J. Gestal-Otero, "A meta-analysis of coffee drinking, cigarette smoking, and the risk of Parkinson's disease," Annals of Neurology, vol. 52, no. 3, pp. 276-284, 2002.

[132] L. S. Honig, G. W. Ross, R. D. Abbott, H. Petrovitch, L. R. White, and C. M. Tanner, "Relationship between caffeine intake and Parkinson disease," JAMA, vol. 284, no. 11, pp. 1378-1379, 2000.

[133] J. Costa, N. Lunet, C. Santos, J. Santos, and A. Vaz-Carneiro, "Caffeine exposure and the risk of Parkinson's disease: a systematic review and meta-analysis of observational studiess," Journal of Alzheimer's Disease, vol. 20, no. 1, pp. S221-S238, 2010.

[134] A. Wang, Y. Lin, Y. Wu, and D. Zhang, "Macronutrients intake and risk of Parkinson's disease: a meta-analysis," Geriatrics and Gerontology International, vol. 15, no. 5, pp. 606-616, 2015.

[135] X. Chen, X. Lan, I. Roche, R. Liu, and J. D. Geiger, "Caffeine protects against MPTP-induced blood-brain barrier dysfunction in mouse striatum," Journal of Neurochemistry, vol. 107, no. 4, pp. 1147-1157, 2008.

[136] K. Xu, Y.-H. Xu, J.-F. Chen, and M. A. Schwarzschild, "Caffeine's neuroprotection against 1-methyl-4-phenyl-1,2,3,6tetrahydropyridine toxicity shows no tolerance to chronic caffeine administration in mice," Neuroscience Letters, vol. 322, no. 1, pp. 13-16, 2002.

[137] J. L. Bata-García, J. Villanueva-Toledo, G. Gutiérrez-Ospina, F. J. Álvarez-Cervera, F. J. Heredia-López, and J. L. GóngoraAlfaro, "Sustained improvement of motor function in hemiparkinsonian rats chronically treated with low doses of caffeine or trihexyphenidyl," Pharmacology Biochemistry and Behavior, vol. 86, no. 1, pp. 68-78, 2007.

[138] J. L. Bata-García, L. Tun-Cobá, F. J. Alvarez-Cervera, J. R. Villanueva-Toledo, F. J. Heredia-López, and J. L. GóngoraAlfaro, "Improvement of postural adjustment steps in hemiparkinsonian rats chronically treated with caffeine is mediated by concurrent blockade of $\mathrm{A}_{1}$ and $\mathrm{A}_{2 \mathrm{~A}}$ adenosine receptors," Neuroscience, vol. 166, no. 2, pp. 590-603, 2010.

[139] A. Kalda, L. Yu, E. Oztas, and J.-F. Chen, "Novel neuroprotection by caffeine and adenosine $\mathrm{A}_{2 \mathrm{~A}}$ receptor antagonists in animal models of Parkinson's disease," Journal of the Neurological Sciences, vol. 248, no. 1-2, pp. 9-15, 2006.

[140] J. F. Chen, K. Xu, J. P. Petzer et al., "Neuroprotection by caffeine and $\mathrm{A}(2 \mathrm{~A})$ adenosine receptor inactivation in a model of Parkinson's disease," The Journal of neuroscience, vol. 21, no. 10, 2001.

[141] M. Pierri, E. Vaudano, T. Sager, and U. Englund, "KW-6002 protects from MPTP induced dopaminergic toxicity in the mouse," Neuropharmacology, vol. 48, no. 4, pp. 517-524, 2005.

[142] H. Kase, "Industry forum: progress in pursuit of therapeutic A2A antagonists-the adenosine A2A receptor selective antagonist KW6002: research and development toward a novel nondopaminergic therapy for Parkinson's disease," Neurology, vol. 61, no. 11, supplement 1, pp. S97-S100, 2003.

[143] R. Dungo and E. D. Deeks, "Istradefylline: first global approval," Drugs, vol. 73, no. 8, pp. 875-882, 2013.

[144] R. A. Hauser, F. Stocchi, O. Rascol et al., "Preladenant as an adjunctive therapy with levodopa in Parkinson disease: two randomized clinical trials and lessons learned," JAMA Neurology, vol. 72, no. 12, pp. 1491-1500, 2015.

[145] B. D. Trapp, L. Bö, S. Mörk, and A. Chang, "Pathogenesis of tissue injury in MS lesions," Journal of Neuroimmunology, vol. 98, no. 1, pp. 49-56, 1999.

[146] M.-A. Lécuyer, H. Kebir, and A. Prat, "Glial influences on BBB functions and molecular players in immune cell trafficking," Biochimica et Biophysica Acta-Molecular Basis of Disease, vol. 1862, no. 3, pp. 472-482, 2016.

[147] E. N. Benveniste, "Role of macrophages/microglia in multiple sclerosis and experimental allergic encephalomyelitis," Journal of Molecular Medicine, vol. 75, no. 3, pp. 165-173, 1997.

[148] F. L. Heppner, M. Greter, D. Marino et al., "Experimental autoimmune encephalomyelitis repressed by microglial paralysis," Nature Medicine, vol. 11, no. 2, pp. 146-152, 2005.

[149] A. R. Simard and S. Rivest, "Bone marrow stem cells have the ability to populate the entire central nervous system into fully differentiated parenchymal microglia," The FASEB Journal, vol. 18, no. 9, pp. 998-1000, 2004.

[150] Z. Yu, D. Sun, J. Feng et al., "MSX3 switches microglia polarization and protects from inflammation-induced demyelination," Journal of Neuroscience, vol. 35, no. 16, pp. 6350-6365, 2015.

[151] S. C. Starossom, I. D. Mascanfroni, J. Imitola et al., "Galectin1 deactivates classically activated microglia and protects from inflammation-induced neurodegeneration," Immunity, vol. 37, no. 2, pp. 249-263, 2012.

[152] X. Chen, X. Ma, Y. Jiang, R. Pi, Y. Liu, and L. Ma, "The prospects of minocycline in multiple sclerosis," Journal of Neuroimmunology, vol. 235, no. 1-2, pp. 1-8, 2011.

[153] A. Wlodarczyk, O. Cédile, K. N. Jensen et al., "Pathologic and protective roles for microglial subsets and bone marrowand blood-derived myeloid cells in central nervous system inflammation," Frontiers in Immunology, vol. 6, article 463, 2015.

[154] A. Shemer and S. Jung, "Differential roles of resident microglia and infiltrating monocytes in murine CNS autoimmunity," Seminars in Immunopathology, vol. 37, no. 6, pp. 613-623, 2015.

[155] Z. Jiang, J. X. Jiang, and G. X. Zhang, "Macrophages: a doubleedged sword in experimental autoimmune encephalomyelitis," Immunology Letters, vol. 160, no. 1, pp. 17-22, 2014.

[156] G. Hasko and P. Pacher, "Regulation of macrophage function by adenosine," Arteriosclerosis, Thrombosis, and Vascular Biology, vol. 32, no. 4, pp. 865-869, 2012.

[157] M. Mayne, P. N. Shepel, Y. Jiang, J. D. Geiger, and C. Power, "Dysregulation of adenosine $\mathrm{A}_{1}$ receptor-mediated cytokine expression in peripheral blood mononuclear cells from multiple sclerosis patients," Annals of Neurology, vol. 45, no. 5, pp. 633639, 1999.

[158] J. B. Johnston, C. Silva, G. Gonzalez et al., "Diminished adenosine $\mathrm{A} 1$ receptor expression on macrophages in brain and blood of patients with multiple sclerosis," Annals of Neurology, vol. 49, no. 5, pp. 650-658, 2001.

[159] G. Q. Chen, Y. Y. Chen, X. S. Wang et al., "Chronic caffeine treatment attenuates experimental autoimmune encephalomyelitis induced by guinea pig spinal cord homogenates in Wistar rats," Brain Research, vol. 1309, pp. 116-125, 2010. 
[160] S. Tsutsui, J. Schnermann, F. Noorbakhsh et al., "A1 adenosine receptor upregulation and activation attenuates neuroinflammation and demyelination in a model of multiple sclerosis," Journal of Neuroscience, vol. 24, no. 6, pp. 1521-1529, 2004.

[161] S. R. Jahromi, M. Toghae, M. J. Jahromi, and M. Aloosh, "Dietary pattern and risk of multiple sclerosis," Iranian Journal of Neurology, vol. 11, no. 2, pp. 47-53, 2012.

[162] E. Rissanen, J. R. Virta, T. Paavilainen et al., "Adenosine A2A receptors in secondary progressive multiple sclerosis: a [11C]TMSX brain PET study," Journal of Cerebral Blood Flow and Metabolism, vol. 33, no. 9, pp. 1394-1401, 2013.

[163] F. Vincenzi, C. Corciulo, M. Targa et al., "Multiple sclerosis lymphocytes upregulate $\mathrm{A} 2 \mathrm{~A}$ adenosine receptors that are antiinflammatory when stimulated," European Journal of Immunology, vol. 43, no. 8, pp. 2206-2216, 2013.

[164] G. Haskó, C. Szabó, Z. H. Németh, V. Kvetan, S. M. Pastores, and E. S. Vizi, "Adenosine receptor agonists differentially regulate IL-10, TNF- $\alpha$, and nitric oxide production in RAW 264.7 macrophages and in endotoxemic mice," Journal of Immunology, vol. 157, no. 10, pp. 4634-4640, 1996.

[165] S.-Q. Yao, Z.-Z. Li, Q.-Y. Huang et al., "Genetic inactivation of the adenosine $A_{2 A}$ receptor exacerbates brain damage in mice with experimental autoimmune encephalomyelitis," Journal of Neurochemistry, vol. 123, no. 1, pp. 100-112, 2012.

[166] J. H. Mills, L. F. Thompson, C. Mueller et al., "CD73 is required for efficient entry of lymphocytes into the central nervous system during experimental autoimmune encephalomyelitis," Proceedings of the National Academy of Sciences of the United States of America, vol. 105, no. 27, pp. 9325-9330, 2008.

[167] J. Ingwersen, B. Wingerath, J. Graf et al., "Dual roles of the adenosine A2a receptor in autoimmune neuroinflammation," Journal of Neuroinflammation, vol. 13, no. 1, article no. 48, 2016.

[168] M. Sitkovsky, D. Lukashev, S. Deaglio, K. Dwyer, S. C. Robson, and A. Ohta, "Adenosine A2A receptor antagonists: blockade of adenosinergic effects and T regulatory cells," British Journal of Pharmacology, vol. 153, no. 1, pp. S457-S464, 2008.

[169] T. Wang, N.-N. Xi, Y. Chen et al., "Chronic caffeine treatment protects against experimental autoimmune encephalomyelitis in mice: therapeutic window and receptor subtype mechanism," Neuropharmacology, vol. 86, pp. 203-211, 2014.

[170] R. Boia, A. F. Ambrosio, and A. R. Santiago, "Therapeutic opportunities for caffeine and A2A receptor antagonists in retinal diseases," Ophthalmic Research, vol. 55, no. 4, pp. 212-218, 2016.

[171] A. R. Santiago, R. Boia, P. Tralhão et al., "Caffeine modulates retinal neuroinflammation and cell survival in retinal ischemia," in Proceedings of the 12th European Meeting on Glial Cells in Health and Disease, p. E178, Glia, Bilbao, Spain, 2015. 


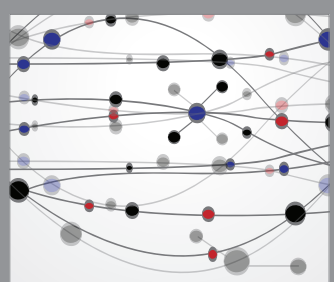

The Scientific World Journal
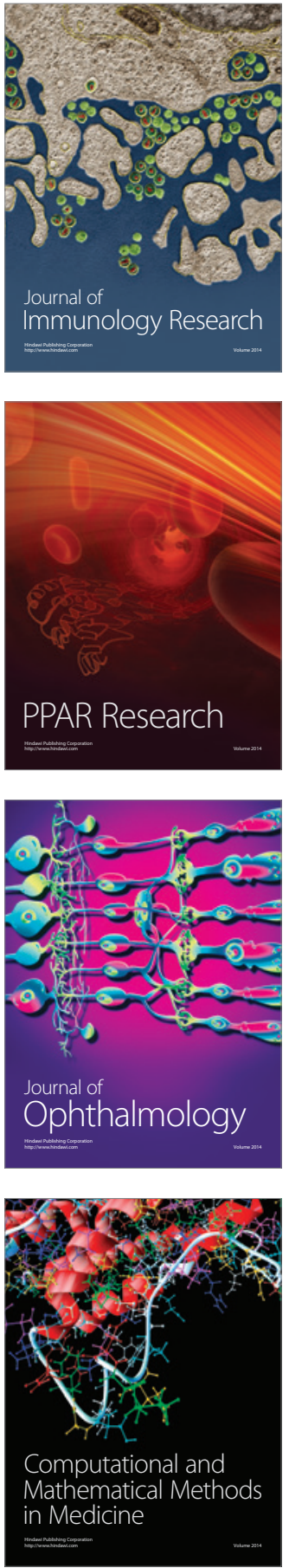

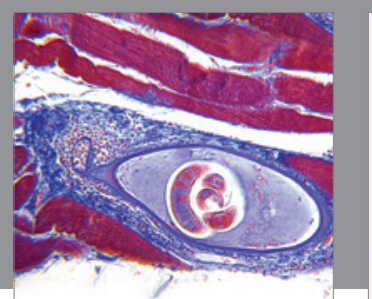

Gastroenterology Research and Practice
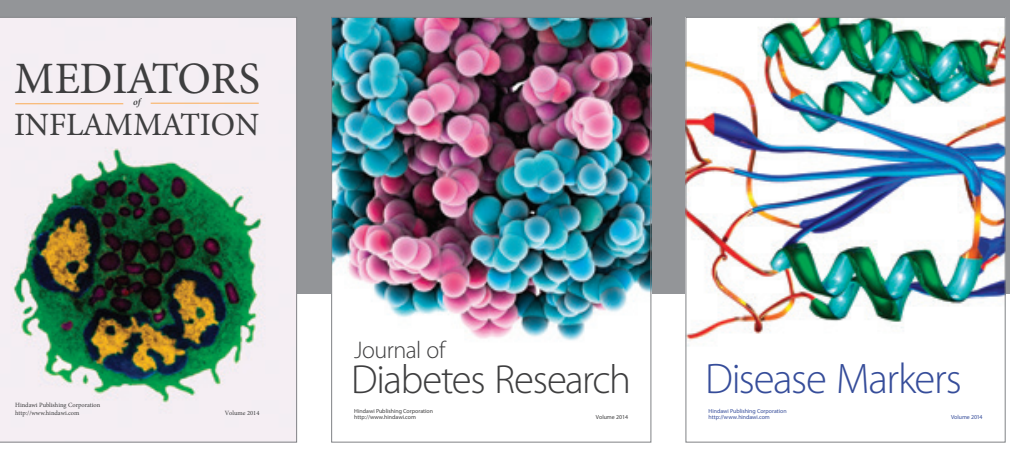

Disease Markers

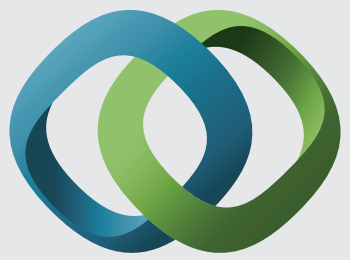

\section{Hindawi}

Submit your manuscripts at

https://www.hindawi.com
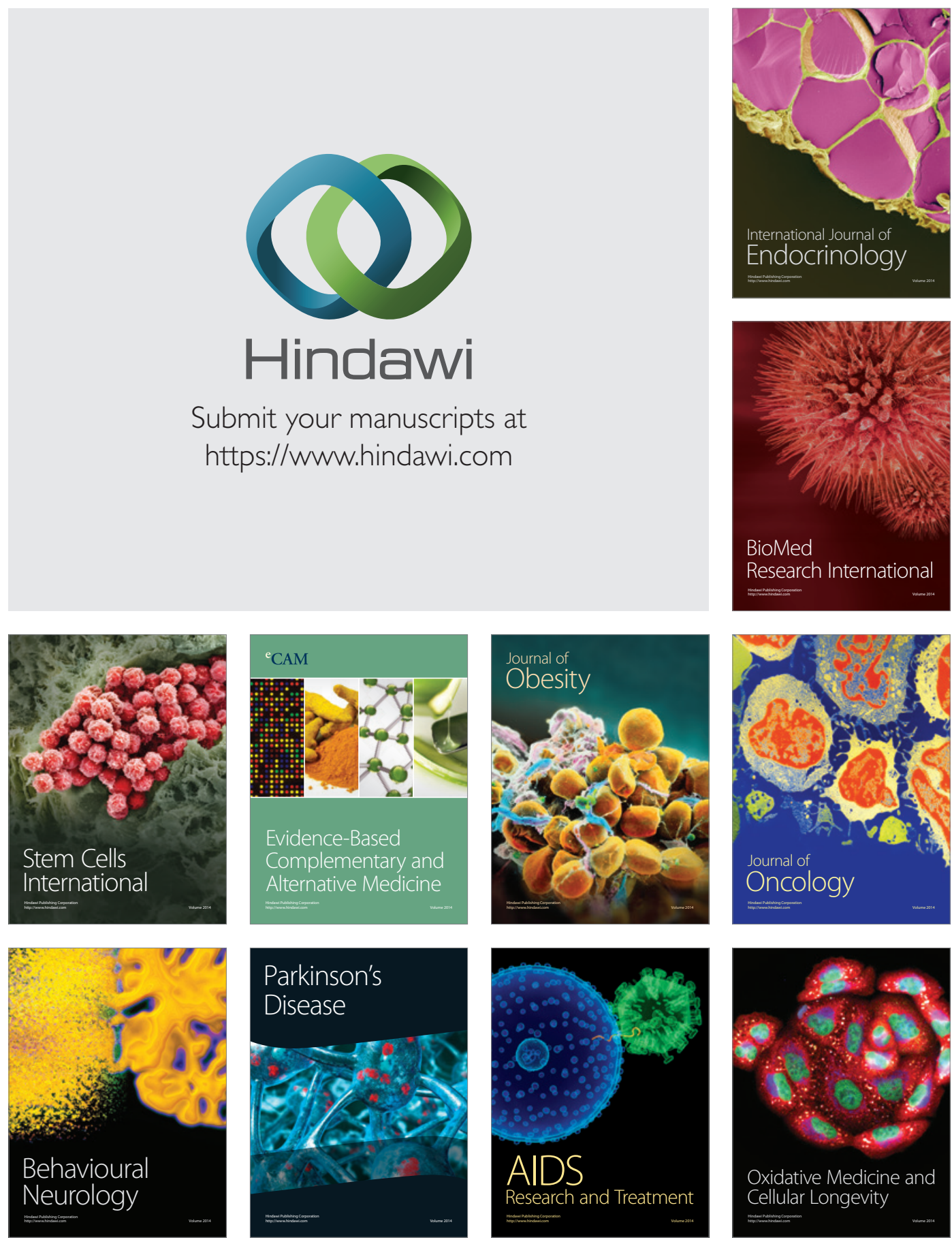